\section{A COMPARATIVE STUDY OF CHINESE MUSICAL ACTIVITIES IN CHINESE AND THAI CULTURAL CONTEXTS}

\author{
Jintana T. Barton ${ }^{1}$
}

\begin{abstract}
This research explores the influence of Chinese music as it is reflected in cultural activities in China and Thailand. In China, music has been used since long before the time of Confucius (551-479 BC) as a learning tool, and the Chinese who migrated into Southeast Asia and ultimately Thailand brought their music with them. In Thai society, Chinese music has been used in traditional ways. Although the music remains closer to what was brought with the immigrants, it has been adopted into Thai society in ways that go far beyond the original Chinese use. This research found that some Chinese musical activities have become ingrained into Thai culture and society such as Lion Dance group performances in the processions for the ceremonial candle (Tian Phansa), the Khan Mak procession, and the Songkran Festival procession. The Lion Dance group also has a photo of a famous Thai monk on the front of a big drum. We also found that the khim is the most popular Chinese musical instrument among Thai people.
\end{abstract}

\footnotetext{
${ }^{1}$ Assistant Professor, Department of Eastern Languages, Faculty of Arts, Chulalongkorn University, Bangkok, Thailand.
}

The khim has been an integral part of Thai classical music for more than one hundred years. Chinese music has become an important cultural integral of both Thai and Chinese cultures.

\section{Introduction}

Music has been and remains, regardless of sporadic and temporary repression, a part of Chinese culture. It is one of the most important legacies of China's past. Music has been mankind's vehicle for transporting stories, poems and language forward and has helped define culture since long before written history. It has been a key to define China's culture in the mainland and in Chinese immigrant societies throughout the world.

The cultural influence of original Chinese music, especially Southern music such as Chaozhou music, has been compared to that of Chinese music as it has developed in Southeast Asia and specifically Thailand. Chinese music is important as an influence in the cultural development of both societies - the cultural influence is perhaps even more important than that of the music itself. Because Chinese music has many activities in Thai culture and society, this research will study the activities of Chinese music in Chinese culture and society, and determine if the effect in the two cultures is the same or different, and what the factors are that change it.

\section{Chinese music in China and Thailand}

\section{Music as a part of Chinese culture}

In ancient times, the Chinese thought music was a necessary subject that man 
should study and it is recorded in the Book of Rites ${ }^{2}$ (礼记 /Lijì) that: 'Scholars don't leave their musical instruments without a reason.' Music is one part of the literati's way of life and music has been very important to the life of people in China.

Confucius (circa 551-479 B.C.), the great Chinese philosopher, was an important influence on the spirit of the Chinese people and made significant contributions to the civilization of the world. He taught the 'Six Arts' (六艺/Liù yì/): ritual, music, archery, chariot riding, calligraphy, and computation. It is also clear that he regarded ritual (morality) as the most important subject, and music as the second most important. He emphasized music, and included music in his educational process. $^{3}$

This research focuses on the Chaozhou and Shantou region. ${ }^{4}$ The combined region of Chaozhou and Shantou is the original homeland of the majority of Chinese who immigrated to other parts of Southeast Asia and particularly into Thailand. The combined region is generally referred to as 'Chaozhou.'

Chaozhou has a wealth of cultural heritage that fostered the Chaozhou dialect, Chaozhou opera, Kongfu tea drinking social customs, Chaozhou folk music, and finally, the unique Chaozhou cuisine. Chaozhou people developed the use of the

\footnotetext{
${ }^{2}$ Book of Rites - the records of ritual of the Zhou Dynasty.

${ }^{3}$ Liu Zai-sheng. (2004) Zhongguo Gudai Yinyue Shi jianshu. [A Brief History of Ancient Chinese Folk music] Beijing: Renmin Chubanshe, p. 79.

${ }^{4}$ This area, located in the northeastern part of Guangdong province, is where most of the Chinese immigrants in Thailand originally came from.
}

'Kongfu tea' drinking custom as a social and cultural activity that combines the discussion of politics, family, and social topics including music. They also love to play and listen to 'Chouzhou music' both during and outside teatime.

Chaozhou people consider Chaozhou opera and music as symbolic of their homeland spirit. $^{5}$ Wherever Chaozhou people settle, they take their musical cultural heritage with them. Chaozhou music is a genre of folk music of Guangdong province in the ChaozhouShantou region where the Chaozhou dialect is spoken. Following is the footsteps of Chaozhou people, the music has spread to southern Fujian province, Taiwan, Hong Kong, Macao and Southeast Asia. ${ }^{6}$

Chaozhou people enjoy studying their traditional Chaouzhou music. The Chaozhou and Shantou area is often called 'Chaozhou - the land of music.'

\section{Chinese music as an imported culture in Thailand}

Many Chinese migrated into Southeast Asia including what is now Thailand. In the thirteenth century A.D., Chinese traders began setting up societies in Thailand's early trading towns at and near

\footnotetext{
${ }^{5}$ Lin Lunlun, Wu Qinsheng. (2001) Chaoshan wenhua daguan [Chaozhou and Shantou culture]. Guangzhou: Huacheng chubanshe, p 270.

${ }^{6}$ Wang Yao-Hua, Du Ya-xiong. (2004) Zhongguo Chuantong Yinyue Gailun [A Brief History of Chinese Traditional Music] Chuanzhou: Fujian Jiaoyu chubanshe, p 286.

${ }^{7}$ Chen Tianguo Su Miaozheng. (2004) Chaozhou yinyue [Chaozhou music] Guangzhou: Guangdong Renmin shubanshe, p.15.
} 
Sukhothai during the Sukhothai period (1279-1438 A.D.). Later, during the Ayutthaya period (1350-1767 A.D.) the Chinese were allowed to develop large Chinese communities in the downtown area, while other foreign communities were required to locate outside the town walls. King Tak Sin, a descendant of ThaiChinese ancestry, established the Thonburi period (1767-1782 A.D.).

During the Rattanakosin (Bangkok) period (1782A.D.-present), many Chinese immigrants settled in Bangkok, especially in the period of King Rama I (1782-1809 A.D.). Chinese people received permission from the King to relocate their community to the Yaowaraj area. It is there today and is still called the 'Chinatown' of Thailand. The majority of Chinese immigrated to Thailand following the end of the Second World War, (1945), since there were no restrictions on immigration at that time. Today, direct descendants of the Chinese make up over 14 percent of Thailand's population. ${ }^{8}$

Chinese immigrants brought their own ceremonies and entertainment with them into Thailand and have inserted the music that supported these ceremonies into their new land and new culture. These include Buddhist ritual music, Chinese New Year parades, opening ceremonies (for a new business, new school, new building), funeral rites, plays and operas.

After Sino-Thai diplomatic relations were established in 1975, both Thai and China initiated many art and culture exchanges. Chinese music has become well known in Thailand through culture exchange and mass media performances, so Thailand has

${ }^{8}$ http://en.wikipedia.org/wiki/Thai_Chinese (July 12, 2007). recently been exposed to arts and culture from many parts of China, not just the Chaozhou region.

Due to the globalization of world communications, young people in Thailand have seen the Twelve Girls Band on MTV. They have come to like Chinese traditional music rhythms and have adopted them in modern ways including both new instruments and playing methods. For example, some Thai groups are learning to stand up when playing Thai classical instruments instead of being seated as before. ${ }^{9}$

\section{Chinese musical activities in China and Thailand}

The activities that occur along with Chinese music include dance, drama, opera, and ceremonial prayer or chant. Chinese musical activities can be divided into four general categories: 1) music for accompaniment, 2) music for entertainment, 3) music for ritual or merit, 4) music for learning.

\section{Music for accompaniment}

\section{Music in Lion Dance}

The Lion Dance combines art, history, and martial arts into an extraordinary performance. Normally, the performers have some martial arts training, as the dance requires suppleness, flexibility, fitness, strength and balance. Every type of movement has a specific musical rhythm and the music mimics the movements of the lion.

\footnotetext{
${ }^{9}$ Thai classical music is traditionally played by musicians who are seated on the floor or a chair.
} 
The drumbeat follows the lion and the cymbals and gong players follow the drum. The whole dance requires precision and each member of the team to be in unison. The Lion Dance is an important tradition and folk art in China, usually performed along with the Dragon Dance on auspicious occasions.

The Lion Dance requires the skills of two performers. One, handling the lion's head, leads the dance and shows the lion's emotions, and the other one plays the body and the tail. They hide under an elaborate cloth cover attached to the head. The Lion Dance is accompanied by musicians playing a drum, a gong and cymbals, and is guided by a man usually holding a fan who entices the lion.

During the dance in China the lion tries to catch the money or green vegetable that is hung over the building's entrance. Sometimes, when the money is held very high, as when offered from an upstairs window, performers may stand on one another's shoulders to catch it. Taking the green vegetable (or money) means 'getting rich - good business', and the lion throws an apple to the owner of the store (the apple conveys peace). In Thailand, lion dancers try to grab only money from high places, and one does not see them grabbing green vegetables or throwing apples as is done in China.

Chinese musical instruments in the Lion Dance include a big drum, a gong and cymbals. The music for the Lion Dance is easy and simple.

In China, dance groups are found all around the country. Local communities, schools, colleges and universities all organize Lion Dance groups.
The Dragon and Lion Dance group at South China Normal University, Guangzhou was observed and studied. This group is a student activity that performs on various occasions and joins the annual Lion and Dragon Dance competition. During Chinese New Year, Lion Dance groups go to perform on the street or in markets and malls. A company sponsors some groups. For example the Budweiser Beer company sponsored a Lion Dance for a Chinese restaurant in Guangzhou. In China the Lion Dance and musician groups walked into the mall and visited every place in the mall (restaurants, pubs, bars, department store), whereas the Lion Dance in Thailand only dances in front of the mall or department store.

The Lion Dance in Thailand is organized by Chinese and Thai community societies. Most of the dancers and musicians are amateurs. For example in Bangkok's Chinatown, a teacher from the Guangzhao Society helped train Traitmitr Middle School's Lion Dance. The group learned how to dance and practiced diligently to perform for the Chinese New Year festival in Bangkok's Chinatown. I found that the Guangzhao Society's lion dance style and rhythm of the music in Bangkok and Guangzhou the same, especially when the dancer starts to dance. They have a boxer style exercise that they do before they put the lion head on.

Lion dancers and musicians are local Thai students or workers. The Lion Dance also takes part in Thai cultural activities, such as Khao Phansa ${ }^{10}$ which marks the

\footnotetext{
${ }^{10}$ Khao Phansa, or the beginning of the Buddhist Lent, is the time when all Buddhist monks are required to remain in their temples. People usually make merit by offering a large candle to the temple.
} 
beginning of the Buddhist lent when the lion dance is featured in processions for the ceremonial candle (Tian Phansa) that is brought to the temple. It also features in the Songkran Festival ${ }^{11}$ and the procession when the bridegroom brings a dowry over to the bride's parents before the wedding ceremony takes place (Khan Mak ${ }^{12}$ ).

The Thai Lion Dance ceremony usually has a photo of a Chinese deity or famous Thai monk on the front of the big drum. Before they perform, dancers show their respects by burning incense and offering liquor. This was not observed in China.

In China, Lion Dance competitions are held in many regions of the country. In Thailand, Lion Dance competitions are also organized, but commercial firms and enterprises usually host these competitions. Local Thais set the rules of the competition. Thailand's Lion Dance competitions not only have Lion Dances, but they also show people-on-people acts with up to five people on one another's shoulders without props. This is frightening to watch, as the topmost person is usually a very small child. This activity was not observed in China.

\section{Music in the Dragon Dance}

The Dragon Dance is an important folk/traditional performance art in China. It was originally performed to please the dragon, which is the deity of water, to ask for rain during drought years. Gradually it became an entertainment and dance form for festive occasions, usually during the Spring Festival (Chinese New Year) and

\footnotetext{
${ }^{11}$ The traditional Thai New Year which falls in April.

${ }^{12}$ A part of the Thai wedding ceremony.
}

Lantern Festival (the first full moon after Chinese New Year).

The dragons built for the dance, usually ranging from several meters to more than 100 meters long, are mainly made of bamboo, wood, cloth and paper, and are elaborately painted. There are poles attached to the belly of the dragon. During the performance, performers hold the poles and raise the dragon, starting the grand dance to the beat of roaring drums. Sometimes a man raises a pearl (a large white ball) and entices the dragon to follow his rhythm.

Chinese musical instruments used for the Dragon Dance include drums, a gong and cymbals. The musical accompaniment for lion dancing is easy and simple. A Dragon Dance requires a large number of dancers, so sometimes a leader blows a whistle to maintain rhythm.

In China, Dragon Dance groups are found around the country, similar to the Lion Dance groups. Local communities, schools, colleges and universities organize Dragon Dance groups in China, whereas Chinese societies, Chinese shrines and a Chinese foundation organize the Dragon Dance in Thailand.

In China, dragon dancers perform for various occasions, especially Chinese festivals (Spring Festival and Lantern Festival), opening ceremonies of sports competitions, and grand opening ceremonies for a building or a department store. In Thailand, the Dragon Dance is often performed in the Chinese Spring Festival cerebrating a Chinese shrine or birthday of a Chinese deity. Because of its auspicious implications, the Dragon Dance also serves in Thai cultural activities, such as ceremonies in the royal palace. In May 
2005, a dragon dance group was part of a special procession organized to celebrate the joyous occasion of the birth of the son of Crown Prince Maha Vajiralongkorn. ${ }^{13}$

The Dragon Dance group of South China Normal University in Guangzhou consists of ten dancers (nine dancers hold the dragon's body and one leader holds the pearl). A group of ten dancers is the standard size for competitions in China.

There are male and female Dragon Dance groups in China. In some cases, Dragon Dance groups comprising elderly women were found in many regions of China, but such groups have not been formed in Thailand.

In China, Dragon Dance competitions are held in many regions of the country. The China Dragon and Lion Dance Association organizes these competitions. Such competitions are not held in Thailand.

Thai Dragon Dance groups in Nakhon Sawan add Naga or Praya Naga ${ }^{14}$ into the group. There are often two high-poles and the dragon and the Naga intertwine and dance on these poles. The Dragon and Naga dancing together in Chinese festivals is an example of the intermingling of Thai and Chinese cultures.

As a sign of purification, the dancers and musicians of the God and Goddess Golden Dragon Dance Group from Pak Nampho in Nakhon Sawan province must abstain from eating the meat of cows, buffaloes, tortoises, frogs and eels, during the period of practice until the performance. This practice was not observed in China.

\footnotetext{
${ }^{13}$ A new Prince was born to Crown Prince Maha Vajiralongkorn in April, 2005.

${ }^{14} \mathrm{Naga}$ is the snake-like God of Rivers.
}

\section{Music in Yingge Dance}

The 'Yingge dance' (英歌舞 /yīnggē wǔ/) is popular in the Chaozhou, Shantou region and in the two cities of Puning and Chaoyang of Guangdong Province.

Performers of "Yingge" hold two sticks. The performers' faces are made up to mimic heroic characters of the famous tale Outlaws of the Marsh ${ }^{15}$ (水浒传/Shuihǔ zhuàn/).

The most important Chinese musical instrument used in the Yingge dance is the drum, sometimes joined by a gong and cymbals. In China, Yingge dancers perform for various occasions, especially Chinese festivals (Spring Festival and Lantern Festival) and grand opening ceremonies (International, national, state level, e.g. arts fair, sports competitions), but in Thailand, the Yingge dance is performed as a Chinese cultural activity, e.g. Chinese festival and Chinese shrine ceremonies.

In the Chumsang Yingge group in Taklee, Nakhon Sawan, the dancers are mostly young Thai men. They dance in the procession of Chinese deities, and after they dance all morning, they change the rhythm of the music to a modern song for dancing like the melody of a disco dance. By then, they are dancing happily, and are often a little tipsy.

\section{Music in Chaozhou Opera}

The Chinese musical instruments used in Chaozhou opera are generally divided into two parts, one side is the string ensemble

\footnotetext{
${ }^{15}$ One of the Chinese classical novels, written in late Yuan-early Ming Dynasty by Shi Naian.
} 
group (弦诗乐/Xiánshī yuè/) and the other side is the percussion group or drum and gong group (锣鼓队/Luógǔ duì). ${ }^{16}$

In China, on the street at the Shantou seashore about 6-8 Chaozhou opera and music groups can be seen every morning. Each group has more than one hundred members. The groups not only sing Chaozhou opera to the accompaniment of live Chaozhou music, but also play cards and mahjong, and drink Kongfu tea while enjoying conversation and exchanging local gossip. Most members are retired people; however, some are actors, musicians and workers who come to join the group and learn how to sing Chaozhou opera. They come to join the group every morning and the activity lasts from $8 \mathrm{AM}$ until noon everyday. They have to move the musical instruments after each exercise. They have a donation box to help defray expenses.

Chaozhou opera in Thailand is sung in both the Chaozhou dialect and Thai language, but mostly Chaozhou, especially when Thai people hold Chaozhou opera performances for charity. They sing more and more in the Thai language, because it is easier for amateurs to learn the lines in a shorter time, and sometimes there are attempts to use Thai musical instruments in the Chinese music group during charity performances.

Chaozhou opera sung in a foreign language in China has not been found. Musical instruments in Thailand and

\footnotetext{
${ }^{16}$ Veekiat Markman (1996). The Reflection of Music culture from "Chowzhow Chinese Opera": A Case study of "Lhao Buang Nee Choong Pung" Group. Master of Arts, (Culture study). Mahidol University. Nakorn Pathom, Thailand. p.30.
}

China are similar; however, they use the cello, a western stringed instrument, in the Chinese music group, but no other foreign instruments.

In Bangkok, most of the members of Chaozhou opera are late middle aged. Many of them are of Thai-Chinese descent, and some are Chinese from Shantou. They all speak Chaozhou dialect and come to sing Chaozhou opera specifically. Many of the members are well-to-do well-dressed businesspeople. Besides singing Chaozhou opera and playing Chaozhou music, they may enjoy a beer or drink Chinese tea and spend time socializing.

\section{Music for Entertainment}

\section{Chinese music in teahouses and restaurants}

In China, Chinese folk music is usually played in teahouses or Chinese restaurants in five-star hotels. Solo Guzheng and string ensembles (2-3 women playing Chinese erhu, pipa or yangqin) were often observed in Guangzhou and Shantou.

In Bangkok, solo guzheng and solo yangqin are common in Chinese restaurants. In Bangkok's Galaxy restaurant Chinese musical instruments are used in the band, e.g. erhu, guzheng, flute and yangqin. Chinese musical instruments played by Thai musicians often present Thai popular songs, Chinese, Japanese, and also popular Western songs according to the nationality of the guests (June 25, 2004).

\section{Amateur musical groups as a hobby}

There are many musical groups in Shantou City. Many of the members are people 
who retired from various careers including musicians, artists, politicians, doctors and government officials. In Chaozhou, each small village has a Luogudui (gong and drum ensemble). The musicians are students, farmers or workers in the village. They practice after dinner, and play in the Spring Festival. They usually join the parade or procession of Chinese deities.

In Bangkok, Ji Tai Kor's string ensemble has an activity on weekends and members are mostly middle-aged people of Chinese descent. In Chon Buri's San De Shantang's Chinese music group, the musicians are local students (8-17 years old). Some are descendants of Chinese immigrants, but most are Thai workers or children of farmers. The music class is sponsored by the San De foundation. The foundation has a van to pick up the students and drive them back home after class. The songs that they learned were Chaozhou folk songs, and some Thai songs, such as the National Anthem, Sadudi Maha Raja or a salute to The King and Queen of Thailand, and the Royal Anthem.

\section{Chinese music in commercial enterprises}

Chinese folk music concerts are usually recorded for commercial reproduction. It is a thriving business since Guangdong province has many joint venture companies and industrial factories. There are many varieties of Chinese folk music records in Chinese markets - for example: 'Enjoy Chinese Classical Music,' 'Guangdong Music,' 'Chaozhou Music,' 'Folk Music,' and 'Nationally Acclaimed Music Masters.'

In Thailand, there are some cassette-tapes and CD's of Chinese folk music, e.g. khim (butterfly-shaped dulcimer) played by Silaphii Tramond, a Thai classical musician and music teacher. Guzheng and erhu played by Li Yang and Li Hui, a well-known Chinese musician, can be found in the Thai market. They perform both Thai popular and classic songs in the recordings. Guzheng and erhu or Thai fiddle (Soo Duong) played by Thai musicians, performing Thai classical songs and mixed with Thai percussion (drum and ching or Thai cymbals), also can be found in the market.

\section{Music for ritual or merit}

\section{Music in the Kong-tek Ceremony}

Kong-tek ('功德'/gōngdé/ in Mandarin) is a Chinese funeral ceremony originally held in Southern China, especially in the Shantou, Chaozhou region. Chinese musical instruments used in the Kong-tek ceremony are similar to those used in Chaozhou opera and can be divided into two parts. One side is a string ensemble, and the other side is a percussion ensemble.

During the Chinese Cultural Revolution (1966-1976), the government endeavored to eliminate all cultural practices, ceremonies and traditional rites deemed to promote superstitions. Emphasis was placed on Socialist ideology in accordance with the teachings of Mao Tse Tung. At present, however, places like Shantou and Chaozhou have recovered much of their culture including the resurrection of this ceremony. The revival can be seen as an attempt on the part of today's people to preserve the rich cultural heritage that China is renowned for.

Wu Qicheng, a Chinese musician who played the big drum in the 'Chengde 
Moral Pavilion' in Huatuo village, Shantou, explained that "The Kong-tek ceremony music ensemble has many sizes involving anywhere from three to fifteen people. The Kong-tek ceremony is held seven days after the death" (February 22, 2005). The ceremony observed for this research was held at the Jinsha Funeral Hall and Chengde Moral Pavilion.

A Kong-tek ceremony conducted by Sambaogeng, a well-known Kong-tek group in Thailand, was observed in October 2004. The group had 16 men, including professional musicians and laymen. ${ }^{17}$ This Kong-tek group has been invited to tour Thailand and internationally. They were dressed and decorated for the Kong-tek ceremony in very beautiful and colorful costumes. Colorful dress for the Kong-tek ceremony was not observed in China.

In Thailand, some Kong-tek groups have adopted Chinese popular melodies for chanting in the ceremony instead of Chinese traditional melodies. ${ }^{18}$ This was not observed in China.

Shen Mu-sheng, a Thai national, and ethnic Chinese musician, said,: "I have performed the Kong-tek ceremony for 30 years. I have tried to shorten the duration of the ceremony, and also to make it appear more solemn" (August 25, 2004). This indicates an evolution in Thai culture not observed in China.

\footnotetext{
${ }^{17}$ Laymen are the group of men who chant and perform during the Kong-tek ceremony.

18 Songphon Sukhumvat. 2002 A Chao Zhou Music: Case Study of klong Toey Liang Lag

Heng Ensemble. Master of Arts. (Music). Mahidol University. Nakorn Pathom. Thailand, p. 6 .
}

$\mathrm{Xu}$ You, a Chinese musician in Puning, visited Thailand in 1993, and during his visit he joined a Kong-tek ceremony group in Chon Buri. He said: "I played music in a Kong-tek ceremony once while I visited Thailand. I found the ceremony to be shorter, and the music simple. I was able to play with them without any rehearsals" (March 21, 2005).

The Thai musicians and laymen in Kongtek groups are professional, but they do this as a sideline career. Most of them have their own business or small store, and the Kong-tek ceremony is usually conducted at nighttime, so it is easy to manage their time. However, in Shantou, Kong-tek musicians make it their only career. The Chinese Kong-tek is normally performed in the Moral Pavilion or local Funeral Hall, so all of the musicians work for the Moral Pavilion.

In Thailand the Kong-tek is held in both Thai and Chinese circles, either at a Chinese temple or a Thai Buddhist temple, and is attended by both Chinese descendants and Thai people. Today live Chinese music is performed in Kong-tek ceremonies only, because Chinese opera is not often performed on stage in the present time. ${ }^{19}$

There is a Kong-tek ceremony in a Thai temple around Bangkok almost every night and the musicians who play for the Kong-tek seldom have the opportunity to perform Chaozhou opera, which they prefer. It is unfortunate that the number of skilled musicians is very limited in Bangkok.

\footnotetext{
${ }^{19}$ Songphon Sukhumvat. (2002), p.5.
} 
Often the royal Thai family includes a Kong-tek ceremony as part of their funeral services. This included the funeral of the Princess Mother of King Rama IX, and most recently, Khun Poom Jenssen, a grandson of Thailand's present King who was killed in the tsunami that hit Phuket in December 2004. At his funeral there was a Kong-tek funeral ceremony sponsored by the Chinese Businessmen's Society. The Royal Kong-tek ceremony comprised a large number of musicians and laymen.

\section{Buddhist ritual music}

The larger ceremonies that take place in a Chinese temple usually have musical accompaniment when the monks pray or chant. In both Thailand and China, the groups that play in these temples have been hired or they may be local groups in the area who have been invited to perform as the temples do not have resident bands or groups.

Chinese musical instruments in Buddhist ritual music comprise the drum, gong, cymbals and the yangqin (Chinese dulcimer) or suona (Chinese wind instrument). Sometimes the erhu is added. Music ensembles can be large or small.

Chen Tianguo and Su Miaozheng, two Chinese scholars, have collected and recorded Buddhism chants, and arranged them into music notes. They taught Chinese monks and Buddhist chant groups how to sing in consistent tones and rhythms. They did this job to organize a systematic chant class in the Kaiyuan Temple in Chaozhou. This class was observed in November 2004. No such classes are found in Thailand.

In October 2004, a performance of Buddhist music was organized by the
Guangdong Buddhism Association, and performed by the Guangdong Buddhism music group. The group performed various forms of Buddhist chants from Mahayana, Hinayana and Tibetan Buddhism. The show presented Buddhist music, chants and dances. The performers were Chinese monks. This concert presented many kinds of Buddhist chants from China. This Buddhist music group toured China. This kind of concert is not observed in Thailand, but would be well received.

\section{Music for learning}

Music has been a popular form of cultural expression since at least the time of Confucius and many Chinese parents send their children to music classes. In Guangzhou, many parents want their child to learn to play western music, especially the piano. It is usually only when they cannot afford the cost of instruments or study fees that they turn to Chinese classic or folk music.

In Shantou, it is the guzheng, which is the most popular Chinese folk musical instrument that Chinese girls love to play. A guzheng class home school at Jin Xin Dasha, Shantou was observed in December 2004. There was a large class (8 students) and a second class for a single student. Huang Guanying, the guzheng teacher, said: "The little girls love to study guzheng, because its sound is very beautiful, and it is easy to learn. A guzheng instrument is not too expensive. I teach both in Chaozhou dialect and Mandarin. The parents like to understand what I teach their child, so they can be a tutor at home in the familiar language" (December 12, 2004).

In Bangkok, guzheng is also the most popular Chinese musical instrument. The 
Oriental Chinese Academy in Bangkok has 120 students in its guzheng class. Guo Yunxiang, a Chinese music teacher from Shantou, has taught Chinese music in Bangkok for almost 20 years. His class is a large class, but he also teaches one-on-one in a large room so that others can observe.

A Chinese music class in Bangkok was observed in a Chinese language school located in one of the big department stores. This music class is a private class where Thai people like to learn to play as a hobby. A study fee is charged. There are many Chinese music classes organized by Chinese foundations that are free of charge. Some classes only teach and prepare the music group to perform for festivals, and some classes are held to teach poor children how to spend their free time and educate them about arts and culture. In some classes in Nakhon Sawan the student is given a little money to take home after class, so there are many poor children who join this kind of class.

\section{Chinese musical instruments in Thai culture and society}

The Chinese musical instrument that is most popular in Thai culture is the khim (butterfly-shaped dulcimer). The khim is a borrowed word from the Chinese Fujian dialect meaning music or musical instrument that is equivalent to '琴' /qín/ in Mandarin. Immigrants brought the khim to Thailand from China. It was played in Chinese opera, and became very famous and popular in Chinatown in the Bangkok period. Thai classical musicians have adopted the khim to play in Thai classical music ensembles for most of the past 100 years. Thai composers have composed many Thai songs using the khim as a solo instrument.
Incidentally, the khim (butterfly-shaped dulcimer) was not seen in China, but is still played and made in Thailand, and Thai children love to learn khim, because it is easy to learn. The price is also not too expensive.

The khim has been developed and integrated into Thai culture over the past hundred years. They are made in many shapes and sizes and the painting on the khim box is a Thai style painting. Today Japanese cartoon pictures are stuck on khim boxes and the box is very colorful and exciting for children. Many schools in Bangkok offer khim classes. Khim teachers are Thai, and they learn to play Thai classical songs, not Chinese songs.

Thai musicians acquired the 'khim' in order to play along with Thai-Chinese music many decades ago and later the 'khim' has merged into Thai culture and ceremonies. It is interesting to note that 'khim and zheng are both Chinese words for the name of a Chinese musical instrument and appear in the Thai dictionary today. Many Thai classical songs are named 'Chin' and are often observed in Thai classical music. Thai musicians enjoyed Chaozhou opera songs and the Chinese style rhythm that they incorporated into their own compositions. They composed these Thai songs having a Chinese style rhythm and named them 'Chin,' which means 'Chinese.' Recently, Thai musicians are trying to use pipa, erhu, dizi and muyu (wooden fish) in their music, but continue to play while sitting on the floor, which is Thai style rather than standing which is the new Chinese style. 


\section{Conclusion}

The research found that some Chinese music activities have become ingrained in Thai society and has taken a prominent part in Thai cultural activities: e.g. the Lion Dance presented in the Khao Phansa, Songkran Festival, and the processions of Khan Mak. Some Dragon Dance groups add Praya Naga into the compositions. The Dragon and Naga dancing together is a sign of the combination of Thai and Chinese cultures.

Chaozhou opera in Thailand is sung in both the Chaozhou dialect and Thai language, but Chaozhou opera sung in a foreign language has not been found in the Chaozhou-Shantou region. The Kong-tek ceremony is held in both Thai and Chinese circles, either at a Chinese temple or a Thai Buddhist temple, and also serves in the royal Thai family's funeral ceremonies. We also found that the khim, the most popular Chinese musical instrument among Thai people, has merged into Thai culture.

The migration of Chinese culture into Thailand has followed the immigrants who brought their music and family customs. However, the evolution of cultural trends is different between the immigrant societies and Mainland China.

For example:

-In China Chinese students are motivated to study music both as a career and as a hobby. Chinese scholars also research Chinese folk musical instruments with the aim of developing new and modified musical instruments and instrumentation. Musicians are developing new techniques in their performances and often find a new style to present in their concerts.

-Whereas in Thailand people study Chinese music primarily for recreation or as a hobby. There are a few professionals, but there is not enough of a market to support many. Thailand uses the talent available for ceremonial and social events. The style of Chinese music in Thailand is a more conservative style, and the ThaiChinese musicians do not experiment much due to the lack of competition and public motivation. Most of their motivation comes from their community, family, temple or just love of the music.

In many instances, local Thai customs have influenced the original Chinese interpretation of music in religious ceremonies and processions honoring deities and expressions of local legends.

Finally, it was observed that the cultural influence of Chinese music on Thai culture is in proportion with the fourteen percent of the Thai population having Chinese origins and honoring those traditions. However, the Thai way of absorbing the best of immigrating cultures while retaining a uniquely Thai application of the cultural impact of Chinese musical heritage remains consistent with historical trends in Thailand.

\section{References}

Chaoju Yanjiu. 2001. [The Research of Chaozhou Opera], Beijing: Zhongguo 
Xiju Chubanshe, Vol 4, 2001.

Chaozhou Yinyue Renwu Zhuan Lue 1999. [Brief-biography of Chaozhou musician]. Beijing: Zhongguo Xijuchubanshe.

Charoenratana, Sayamol. 2001. "Teochiu Chinese Opera" as a Social Drama: Ethnic Symbol of Thai-Chinese People. Master of Arts, (Anthropology). Chulalongkorn University. Bangkok, Thailand.

Hanchu, Chen. 2005. Chaosu Congtan [Talk about Traditional in Chaozhou] Shantou: Shantou Daxue chubanshe.

Huang, Teng. 2002. Chaoshan Wenhua Yuanliu 2002. [The Resource of Chaozhou and Shantou's Culture]. Guangzhou: Guangdong Gaodeng Jiaoyu Chubanshe.

Liewen, Fang. 2000. Chaoshan Minsu daguan [Introduction to Chaoshan Folklore]. Shantou: Shantou Daxue Chubanshe.

Lin Lunlun, Wu Qinsheng. 2001. Chaoshan Wenhua Daguan [Research of Chaozhou and Shantou Culture]. Guangzhou: Huacheng Chubanshe.

Markman, Veekiat. 1996. The Reflection of Music culture from "Chowzhow Chinese Opera": A Case study of "Lhao Buang Nee Choong Pung" Group. Master of Arts, (Culture study). Mahidol University. Nakorn Pathom, Thailand.

Miaozheng, Chen Tianguo Su. 1998. Chaozhou Yinyue Yanjiu [Chaozhou Music Research]. Guangzhou: Huacheng Chubanshe.
. Chaozhou Yinyue. 2004.

[Chaozhou Music] Guangzhou: Guangdong Renmin Shubanshe.

Sukhumvat, Songphon. 2002. A Chao Zhou Music: Case Study of Klong Toey Liang Lag Heng Ensemble. Master of Arts, (Music). Mahidol University. Nakorn Pathom, Thailand.

Wang Yao-Hua, Du Ya-xiong. 2004. Zhongguo Chuantong Yinyue Gailun [A Brief History of Chinese Traditional Music], p 286. Chuanzhou: Fujian Jiaoyu Chubanshe.

Weishen, Wang. 2004. Chaoshan Suyu Wenhua Qutan [Talk about Culture and Idiom in Chaozhou and Shantou Region], Shantou: Shantou Daxue Chubanshe.

Zai-sheng, Liu. 2004. Zhongguo Gudai Yinyue Shi jianshu [Brief in Historical of Ancient Chinese Folk music] Beijing: Renmin Chubanshe.

Zhongguo Lishi Wenhua Mingcheng: Chaozhou. 2002. [Chinese Cities of Historical and Culture Fame: Chaozhou] Suzhou: Guwuxuan chubanshe.

http://chaoju.shantou.gov.cn/ (May 12, 2006)

http://en.wikipedia.org/wiki/Thai_Chinese (July 12, 2007)

http://www.chaoju.com/ (July 2, 2005)

http://www.csfqw.com/music/default.html (July 10, 2006)

http://www.csfqw.com/music/a/article_11 066_1.html (June 8, 2005)

http://www.thaikids.com (April 20, 2007) 